Noname manuscript No.

(will be inserted by the editor)

\title{
Impact of the Equatorial Atlantic on the El Niño
}

\section{Southern Oscillation}

\author{
Hui Ding · Noel S. Keenlyside • Mojib \\ Latif
}

Received: date / Accepted: date

\begin{abstract}
Observations indicate that the Atlantic zonal mode influences El Niño Southern Oscillation (ENSO) in the Pacific, as already suggested in previous studies. Here we demonstrate for the first time using partial coupled experiments that the Atlantic zonal mode indeed influences ENSO. The partial coupling experiments are performed by forcing the coupled general circulation model (ECHAM5/MPI-OM) with observed sea surface temperature (SST) in the Tropical Atlantic, but with full air-sea coupling allowed in the Pacific and Indian Ocean. The ensemble mean of five members simulations reproduce the observational results well.
\end{abstract}

Hui Ding

IFM-GEOMAR, Düsternbrooker Weg 20, Kiel 24105, Germany

Tel.: +49-431-6004071

Fax: +49-431-6004052

E-mail: hding@ifm-geomar.de 
Analysis of observations, reanalysis, and coupled model simulations all indicate the following mechanism: SST anomalies associated with the Atlantic zonal mode affect the Walker Circulation, driving westward wind anomalies over the equatorial Pacific during boreal summer. The wind stress anomalies increase the east-west thermocline slope and enhance the SST gradient across the Pacific; the Bjerknes positive feedback acts to amplify these anomalies favouring the development of a La Niña-like anomalies. The same mechanisms act for the cold phase of Atlantic zonal mode, but with opposite sign. In contrast to previous studies, the model shows that the influence on ENSO exists before 1970. Furthermore, no significant influence of the Tropical Atlantic on the Indian Monsoon precipitation is found in observation or model.

Keywords ENSO · Atlantic zonal mode $\cdot$ Teleconnection $\cdot$ Bjerknes feedback

\section{Introduction}

In the tropical Pacific, the El Niño Southern Oscillation is the dominant mode of interannual climate variability. It results from ocean-atmosphere interaction (Bjerknes, 1969; Philander, 1990). ENSO extremes often begin in boreal spring and summer and reach their peak in boreal winter. The changes in the atmospheric circulation caused by ENSO affect weather around the world (e.g., Glantz et al, 1991), having large economic and social impacts. In the equatorial Atlantic, the dominant mode of interannual variability results from similar ocean-atmosphere interaction (Zebiak, 1993; Xie and Carton, 2004; Keenlyside and Latif, 2007; Jansen et al, 2009; Ding et al, 2010), and is termed the "At- 
lantic zonal mode" or "Atlantic Niño". However, in the Atlantic, the variability has different seasonality, and anomalous events in sea surface temperature (SST) often reach their mature phase during boreal summer (Keenlyside and Latif, 2007).

Recent studies have suggested that Atlantic zonal mode variability may influence ENSO (Wang, 2006; Keenlyside and Latif, 2007; Jansen et al, 2009; Rodríguez-Fonseca et al, 2009; Losada et al, 2009; Wang et al, 2009). Wang (2006) found that Tropical Atlantic and Pacific SST anomalies form an interbasin gradient and positive feedback with overlying Walker Circulation, indicating an interaction between the two tropical ocean basins. Keenlyside and Latif (2007) indicate there is a significant correlation between Atlantic and Pacific Niños, when the Atlantic leads by six-months. Conceptual models for equatorial Pacific and Atlantic variability derived from observations indicate a feedback from the Atlantic on ENSO exists, and can enhance ENSO prediction skills (Jansen et al, 2009). Losada et al (2009) studied the tropical response to the Tropical Atlantic SST anomalies using four atmospheric general circulation models (AGCMs). Their results show that the SST anomalies produce a Gilltype response, which extends into eastern Tropical Pacific. Rodríguez-Fonseca et al (2009) investigated the Tropical Atlantic influence on ENSO from a coupled perspective. Analysing observations and reanalysis, they showed that Atlantic zonal mode events are associated with surface wind anomalies in boreal summer in the Equatorial Pacific. They argued that these are subsequently amplified by the Bjerknes positive feedback, causing an ENSO extreme peaking 
in the boreal winter, thus explaining the significant correlation when Atlantic variability leads that in the Pacific by six-months (Keenlyside and Latif, 2007). To support the mechanisms they performed ensemble simulations with a coupled model (an AGCM coupled to 1.5 layer ocean model) with observed SST prescribed in the Atlantic, but fully coupled elsewhere. However, their model results are not entirely consistent with observations. Specifically, the observed consistent signal among wind stress, thermocline depth and sea surface temperature from the boreal summer to winter was not well reproduced. Thus, it is worthwhile to re-investigate the mechanism for the influence of the Tropical Atlantic on ENSO.

Keenlyside and Latif (2007) found that Atlantic zonal mode's influence on ENSO is weaker, but remains significant, before 1970 by employing linear correlation analysis to observations. Rodríguez-Fonseca et al (2009) argues that the influence does not exist before 1970 in either observations or their model. They argue that the change is associated with 70's climate shift reported in previous studies. However, internal physical process in the Tropical Pacific may make it difficult to isolate the influence by employing linear correlation to relatively short records. We will further investigate this topic in this study.

Several recent studies show that the Atlantic zonal mode may also influence the Indian Monsoon (Kucharski et al, 2007, 2008, 2009; Losada et al, 2009). Using an AGCM coupled to the MICOM ocean model in the Indian Ocean, Kucharski et al (2007) argued that the Atlantic zonal mode variability regulates the relationship between Indian Monsoon Rainfall and ENSO. 
Losada et al (2009) investigated the atmospheric response to SST anomalies associated with Atlantic zonal mode using four AGCMs. Their model results show that the atmospheric response extends into the Indian Ocean. However, as discussed above, the Atlantic zonal mode may affect ENSO and thus indirectly also the Indian Ocean (Klein et al, 1999; Xie et al, 2002; Krishnamurthy and Kirtman, 2006). However, what is the net influence if we consider both direct and indirect effects on the Indian Ocean? A model coupled over the Tropical Pacific and Indian Oceans is required to answer this question and to study the Tropical Atlantic's influence on the Indian Monsoon, a strategy that we follow here.

Here, we employ a fully coupled climate model (ECHAM5/MPI-OM) to address the questions presented above. In section 2, we give a brief introduction to the model employed in this study and the experimental design. In section 3 , the mechanisms are identified by analysing the coupled model experiments. Discussion and conclusions are given in section 4 .

\section{Data, Model and experimental setups}

Sea surface temperature data are taken from the Hadley Center Sea Ice and Sea Surface Temperature dataset version 1.1 (HadISST 1.1), which is an EOF-based reconstruction of observations extending from 1870 to present (Rayner et al, 2003), and are provided by the British Atmospheric Data Center (http://badc.nerc.ac.uk/home/). Sea level pressure (SLP) and wind stress are taken from NCEP/NCAR reanalysis (Kalnay et al, 1996). Stream function 
and velocity potential are calculated from NCEP/NCAR zonal and meridional wind components (Kalnay et al, 1996). CMAP satellite derived precipitation data (Xie and Arkin, 1997) are available from 1979 up to present, provided by the NOAA/OAR/ESRL PSD, Boulder, Colorado, USA (http://www.esrl.noaa.gov/psd/). Thermocline depth data is calculated from NCEP ocean temperature reanalysis, which is available from 1980 to present.

In this study, the Max-Planck-Institute (MPI) coupled model ECHAM5/MPIOM (IPCC version, AR4) is employed. The atmosphere model (ECHAM5) is run at T63 spectral resolution $(1.875 \times 1.875)$ with 31 vertical (hybrid) levels. The ocean (MPI-OM) has 1.5 degree average horizontal grid spacing with 40 unevenly spaced vertical levels. Atmosphere and ocean are coupled by means of the Ocean-Atmosphere-Sea Ice-Soil (OASIS) coupler (Valcke et al, 2003). The model does not require flux adjustment to maintain a stable climate, and simulates the mean state, and annual and interannual variability in the Tropical Pacific well: Mean deviations from observed sea surface temperature is less than $1 \mathrm{~K}$ over much of the Tropical Pacific, and the phase and strength of the simulated annual cycle of SST in the equatorial Pacific match observations (Jungclaus et al, 2006). The simulated ENSO has a dominant period of around 4 years, and its spatial pattern is in agreement with observations. The model has been used in climate predictability and prediction studies (e.g., Keenlyside et al, 2008).

Here a partial coupled configuration of the model is used, with full coupling everywhere except in the Atlantic, where model SSTs are nudged to observa- 
tions: between $30^{\circ} \mathrm{S}$ and $30^{\circ} \mathrm{N}$ the damping constant (e-folding time) amounts

to $0.25 d^{-1}\left(3.8 \times 10^{3} \mathrm{Wm}^{-1} \mathrm{~K}^{-1}\right.$ for $10 \mathrm{~m}$ upper ocean-layer $)$; poleward of these latitudes the damping constant decreases linearly to zero at $60^{\circ} \mathrm{S}$ and $60^{\circ} \mathrm{N}$. Here, full observed SST is nudged into the model. SST anomalies are not used because the model exhibits a warm SST bias in the Tropical Atlantic, a feature common to most CGCMs (Davey et al, 2002; Richter and Xie, 2008; Wahl et al, 2009). National Center for Environmental Prediction (NCEP) reanalysis (Kalnay et al, 1996) skin temperature (obtained from the Climate Diagnostics Center; see http.//www.cdc.noaa.gov) is used to force the model. It is run from 1950 to 2005 with five ensemble members, differing in the initial conditions. Prior to 2000, radiative forcing is computed from observed changes in greenhouse gas concentrations, sulphate aerosol loadings, and the solar cycle, and accounts for major volcanic eruptions; after 2000 it follows the IPCC A1B scenario.

\section{Atlantic zonal mode's influences on ENSO}

Rodríguez-Fonseca et al (2009) hypothesized a mechanism of how Atlantic zonal mode influences ENSO by analyzing observations and reanalysis. However, observations offer only one realization and the relationship could be incidental. Their model could not provide convincing support for the hypothesized mechanism. Here we confirm the relationship revealed by observations and reanalysis by performing a set of experiments with a full CGCM in which observed SST is prescribed in the Atlantic (See section 2 for details); the ex- 
perimental design is similar to that of Rodríguez-Fonseca et al (2009). The ensemble mean of these simulations is analyzed. It reduces the contribution of internal dynamics in the Indo-Pacific sector by a approximately 0.45 , while retaining the influence from the Tropical Atlantic. For the sake of completeness, we compare our model results with those of observations and reanalysis; however, the observational analysis is essentially that published by RodríguezFonseca et al (2009).

The observed relation between Atlantic zonal mode and ENSO was particularly strong since 1968 (Kozlenko et al, 2009; Rodríguez-Fonseca et al, 2009), and thus the period since 1970 is only considered here, unless otherwise stated. However, as discussed below, modelling results indicate that observed changes in relationship are largely fortuitous, and that the relation is stationary.

The observed cross correlation between Niño3 $\left(150^{\circ} \mathrm{W}-90^{\circ} \mathrm{W}, 5^{\circ} \mathrm{S}-5^{\circ} \mathrm{N}\right)$ SST and Atlantic cold tongue $\left(20^{\circ} \mathrm{W}-0^{\circ} \mathrm{W}, 6^{\circ} \mathrm{S}-2^{\circ} \mathrm{N}\right) \mathrm{SST}$ shows that no significant relation exists at zero lag or when Pacific variability leads (Fig. 1), consistent with previous studies (Enfield and Mayer, 1997; Chang et al, 2006). Chang et al (2006) shows that dynamical and thermodynamical mechanisms compete, causing a insignificant influence of ENSO on Atlantic zonal mode. In contrast, a statistically significant anti-correlation of -0.42 exists when the Atlantic cold tongue index leads Niño3 SST variations by about six months (Fig. 1) (Keenlyside and Latif, 2007). This alone does not necessarily indicate that the Atlantic zonal mode affects ENSO, as statistical relations do not prove causality. 
The model simulation with observed SST prescribed in the Atlantic well reproduces the observed relation between Atlantic cold tongue and Nino3 SST anomalies (Fig. 1). In particular, the model reproduces the maximum anticorrelation when the Atlantic cold tongue index leads Niño3 SST by about six months. This indicates that in response to prescribed warm (cold) SST anomalies associated with the Atlantic zonal mode, the model tends to simulate cold (warm) SST anomalies in the Pacific. There exist some discrepancies between the observations and the model. For instance, the model displays a simultaneous anti-correlation of -0.3 , while the observations display no simultaneous relationship. This discrepancy is not surprising given that the Atlantic SST in the model cannot be influenced by variability in the Pacific, as they are prescribed. And ensemble averaging isolates the one-way interaction. The good agreement between observations and model provides confidence to use the model to further investigate the mechanisms connecting variability in the two basins. In particular, we now carefully compare observed and simulated fields associated with the Atlantic zonal mode in boreal summer and the following winter.

Associated with warm SST anomalies (Fig. 2a and b) of the Atlantic zonal mode in boreal summer, there are positive precipitation anomalies (Fig. 2a and b) in the equatorial Atlantic region. The corresponding diabatic heating produces a pair of anti-cyclone and divergent motion over the Tropical Atlantic at $200 \mathrm{hPa}$ (Fig. 2e and f). The atmospheric response at this level also extends into the Tropical Pacific with a pair of cyclone and a convergent motion there 
(Fig. 2e and f). There are low and high sea level pressure anomalies (Fig. 2g and h) in the Tropical Atlantic and Pacific, respectively. These correspond to ascending and descending motions (Fig. $2 \mathrm{~g}$ and $\mathrm{h}$ ) at the $500 \mathrm{hPa}$, respectively. The high pressure and descending motion anomalies (Fig. $2 \mathrm{~g}$ and $\mathrm{h}$ ) in the Tropical Pacific suppress convective activity and reduce precipitation there (Fig. 2a and b). The sea level pressure anomalies further produce easterly wind stress anomalies (Fig. 2c and d). In general, the coupled model with observed SST prescribed in the Tropical Atlantic reproduces the observed relationships (Fig. 2) between atmospheric circulation anomalies and Atlantic zonal mode variability well in both amplitude and phase.

Forced by the easterly wind stress (Fig. 2c and d) associated with the warm SST anomalies of the Atlantic zonal mode, equatorial Pacific thermocline slope is increased, with shoaling and deepening in the east and west (Fig. 2c and d), respectively. The shallower thermocline (Fig. 2c and d) in the eastern equatorial Pacific reduces SST there (Fig. 2a and b). In the following autumn (not shown) and winter (Fig. 3), the anomalies in wind stress, thermocline depth and SST are enhanced through the Bjerknes positive feedback. And anomalies resemble those of a La Niña event. In boreal winter, regression coefficient in SST fields (Fig. 3a and b) is about $0.8-1.0^{\circ} \mathrm{C}$ in the eastern equatorial Pacific. The standard deviation of SST anomalies averaged over Atlantic cold tongue is about $0.5^{\circ} \mathrm{C}$ in boreal summer. This means that on average, Atlantic zonal mode could produce SST anomalies of about $0.4-0.5^{\circ} \mathrm{C}$ in the eastern equatorial Pacific in boreal winter. The comparison above shows that 
the mechanism for the Atlantic zonal modes influence on ENSO in the coupled model is very similar to that previously suggested (Rodríguez-Fonseca et al (2009)) from observations and reanalysis. In contrast to analysis of observations, where causality can not be determined and results may simply arise by chance, the ensemble mean of the five model runs strongly indicates the existence of a physically robust influence of the Atlantic Zonal mode on Pacific interannual variability.

To investigate how much SST variability is associated with Atlantic zonal mode, the simultaneous correlation (Fig. 4a) is calculated between model and observations for all months from 1970 to 2005. In the eastern equatorial Pacific, the correlation is above 0.3 and even reaches 0.4 at some points; this indicates that about $10 \%$ of the SST variability in this region is related to the Atlantic zonal mode. In the north-western and south-western Tropical Pacific and western Tropical Indian Ocean, the correlation is also high and up to 0.3 (i.e., also explaining $10 \%$ of the SST variability). The monthly stratified correlation between model and observed Niño3 SST (Fig. 4b) shows larger values in boreal spring and summer (up to 0.5) than in winter (0.3). This indicates that compared to internal dynamics in the Tropical Pacific, the signal from the Atlantic zonal mode is more important in boreal spring and summer than in winter. Therefore, it is possible for a signal from Atlantic zonal mode to influence the evolution of ENSO during these months. The simultaneous correlation (Fig. 4c) is also calculated between model and NCEP reanalysis thermocline depth for all the months (1980-2005). In the equatorial Pacific, the correlation 
is up to 0.3 in the east and 0.4 in the west, respectively. This shows that about $10 \%-15 \%$ of the thermocline depth variability in the Pacific equatorial belt is associated with the Atlantic zonal mode. Considering the influence of Atlantic on Tropical Pacific variability, it is interesting to ask whether Atlantic zonal mode could trigger or just modulate on-going ENSO events. How much could condition in the Tropical Pacific affect the remote forcing from Atlantic zonal mode? These questions are beyond this study, and we leave them for future work.

\section{Conclusion and discussion}

In this study we investigate the mechanisms of how the Atlantic zonal mode in boreal summer affects ENSO during boreal winter using the ECHAM5/MPIOM CGCM, focusing on the period 1970-2005. Five ensemble member simulations forced by observed SST in the Tropical Atlantic, but with full air-sea coupling allowed in the Pacific and Indian Oceans were performed for the period 1950-2005. The model reproduces the observed relation and previously suggested teleconnection mechanism (Rodríguez-Fonseca et al, 2009) well. Warm SST anomalies of Atlantic zonal mode affect the Walker Circulation, driving easterly wind stress anomalies over the western to central equatorial Pacific. This increases thermocline's east-west slope with shoaling and deepening in the eastern and western Pacific, respectively. The shallower thermocline in the east cools SST there, and cold SST anomalies further produce more eastward wind stress in the west. In the following autumn and winter, these anomalies 
in wind stress, thermocline and SST are amplified further by the Bjerknes positive feedback, favouring the development of a La Niña-like anomalies. The same mechanism works for cold phase of Atlantic zonal mode, but with opposite sign.

The coupled model provides a strong support for the mechanism, and this result goes beyond previous studies (Losada et al, 2009; Rodríguez-Fonseca et al, 2009). In the study by Losada et al (2009) only AGCMs were employed, and thus only the direct atmospheric response could be simulated, but not the subsequent amplification by Bjerknes positive feedback. Rodríguez-Fonseca et al (2009) did employ a coupled model with prescribing SST in the Tropical Atlantic. While their approach is very similar to ours, their model results were not entirely consistent with observations and thus could not support strongly the proposed mechanism. In particular, while the model showed negative SST anomalies in the east Pacific in boreal winter, the amplitude is much weaker than that in observations. More importantly, their model did not show any significant signals associated with Atlantic zonal mode in wind stress, eastwest gradient in thermocline depth and SST in the equatorial Pacific in boreal summer. The mechanism revealed by both observations and the coupled model experiments in this study show that these signals in boreal summer, which are seeded by the Atlantic zonal mode, are crucial to the following evolution of ENSO.

Another aspect that is different from Rodríguez-Fonseca et al (2009) is that our model results also reveal a significant influence of Atlantic zonal mode on 
ENSO before 1970 with an anti-correlation of -0.4 when Niño3 SST anomalies lag by about 9 months (Fig. 5a). Rodríguez-Fonseca et al (2009) argues that the influence does not exist before 1970 based on the cross correlation in observations (Fig. 5a) and their model, indicating non-stationary behavior. However, as discussed before, the observations are only one realization, and internal physical processes in the Tropical Pacific are still dominant in the evolution of ENSO; the latter can be seen from the small variances explained by Atlantic zonal mode (Fig. 4). This could make it difficult to isolate the influence by applying linear correlation to a comparatively short observational period. We performed an ensemble to damp internal dynamics in the Tropical Pacific. Consistently, although the ensemble mean does reproduce the cross correlation revealed by observation since 1970 (Fig. 1), it is not reproduced by every single member (Fig. 5b).

Interestingly, there are also significant influences of the Atlantic zonal mode on the Indian Ocean and the western Pacific. For instance, precipitation anomalies (Fig. 2a and b) appear in the eastern Indian Ocean and western Pacific in boreal summer. In the following autumn (not shown) and winter (Fig. 3a and $\mathrm{b})$, the anomalies extend northeastward and southeastward, respectively, covering a large part of the western Pacific and eastern Indian Ocean. In these regions, there are also positive SST anomalies (Fig. 3a and b). The model also reproduces these precipitation and SST anomalies (Fig. 3a and b). However, these relations may not reflect a direct influence by the Atlantic 
zonal mode (Kucharski et al, 2007), but rather an indirect influence of the induced Pacific variability.

Over the Indian peninsula, neither observation nor our model simulations show significant precipitation anomalies in boreal summer. Anomalies in atmospheric circulation are also not significant there during this season. These findings are different from previous studies (Kucharski et al, 2007, 2008, 2009; Losada et al, 2009) that argue that warm SST anomalies in the Tropical Atlantic produce descending motion and reduce rainfall over the Indian peninsula in boreal summer. These studies either employed a regional coupled model for the Indian Ocean (Kucharski et al, 2007, 2008, 2009) or AGCMs (Losada et al, 2009). In both cases, ocean-atmosphere coupling over the Pacific is excluded. However, previous studies (Wang, 2006; Rodríguez-Fonseca et al, 2009) and this study indicate that Tropical Pacific variability is not independent of the Atlantic zonal mode. We speculate that direct and indirect influences compete over the Indian peninsula. On the one hand, warm SST anomalies in the Tropical Atlantic reduce rainfall there (Kucharski et al, 2007, 2008, 2009; Losada et al, 2009). On the other hand, the warm SST anomalies produce cold SST anomalies in the eastern Pacific. The cold SST anomalies of ENSO enhance rainfall on the Indian peninsula. These two mechanisms compete and may result in an insignificant linear relationship in both observations and the model.

This work implies that seasonal forecast of ENSO could be improved through correctly predicting the SST anomalies associated with Atlantic zonal mode. 
Previous studies (Jansen et al, 2009; Ding et al, 2010) show that there exists some predictability in the Atlantic zonal mode. However, the major systematic errors of complex models (Davey et al, 2002; Richter and Xie, 2008; Wahl et al, 2009) in simulating the equatorial Atlantic climate need to be reduced before useful skill might be realised. In this case, perfect seasonal forecast experiments by specifying observed SST in the Tropical Atlantic can be useful to test the potential improvement on forecasting ENSO (in preparation).

Here, we show the influence of Atlantic zonal mode on ENSO. However, Atlantic zonal mode is not self-sustained (e.g., Zebiak, 1993), but dependent on external forcing, for instance ENSO (e.g., Enfield and Mayer, 1997; Carton and Huang, 1994; Latif and Barnett, 1995; Latif and Grötzner, 2000; Chiang and Sobel, 2002; Chiang and Lintner, 2005; Chang et al, 2006). It is difficult to assess how much of SST variability associated with Atlantic zonal mode is dependent on ENSO. If Atlantic zonal mode were completely dependent on ENSO, then the results here would be best considered as describing a feedback on ENSO. And this in turn would imply that variability in the Atlantic may not be useful in increasing ENSO prediction skill, but this deserves further investigation. Another caveat is that this study investigates the relationship only between summer Atlantic cold tongue and winter Niño3 SST anomalies. The monthly stratified cross correlation (not shown) in both observations and model, however, show that the lead lag relationship also exists in other seasons. This is somewhat puzzling and has not been fully understood yet. The result shows that the mechanism may not be the only one which operates. A control 
run in fully coupled climate model may help to address some of these issues. However, fully coupled GCM are still not adequate for such an investigation, as they display large systematic errors in simulating equatorial Atlantic climate (Davey et al, 2002; Richter and Xie, 2008; Wahl et al, 2009). 
Cross correlation: Nino3 Vs Atlantic cold tongue SST

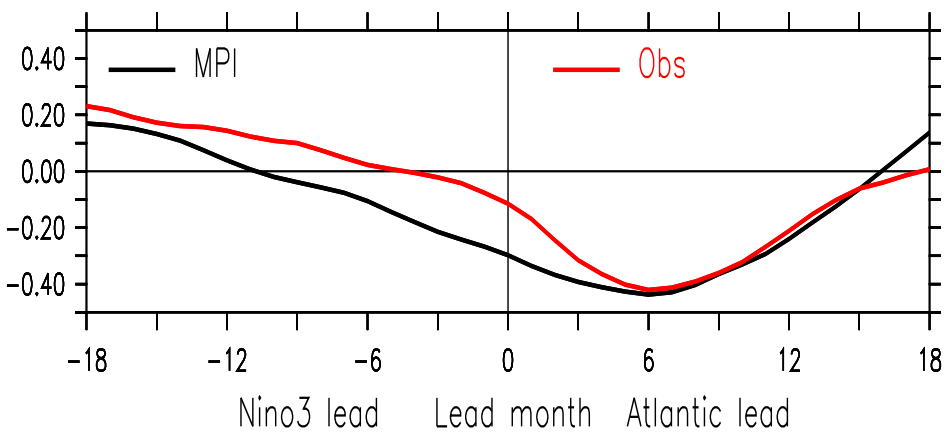

Fig. 1 Cross correlation (1970-2005) between Niño3 and Atlantic cold tongue SST for HadISST (red) and the ensemble mean of the MPI model simulations with observed SST prescribed in the Atlantic (black). The maximum anti-correlations (-0.42) are over $95 \%$ statistically significant under a Student t-test. 
(a) SST and precipitation (OBS)

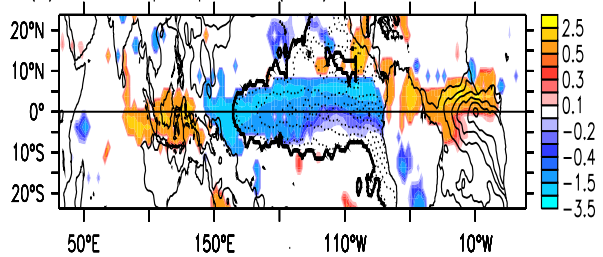

(b) SST and precipitation (MPI)

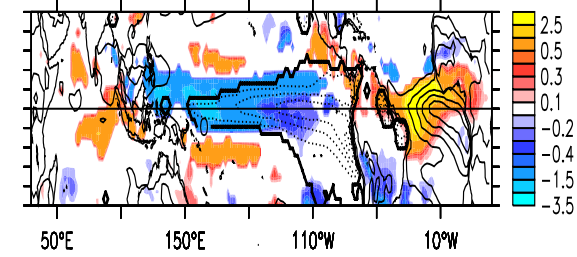

(d) 220 and wind stress (MPI)

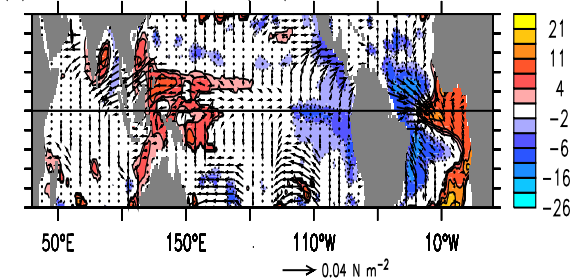

(f) Velocity potential and streamfunction (MPI)

(e) Velocity potentiol and streamfunction (NCEP)
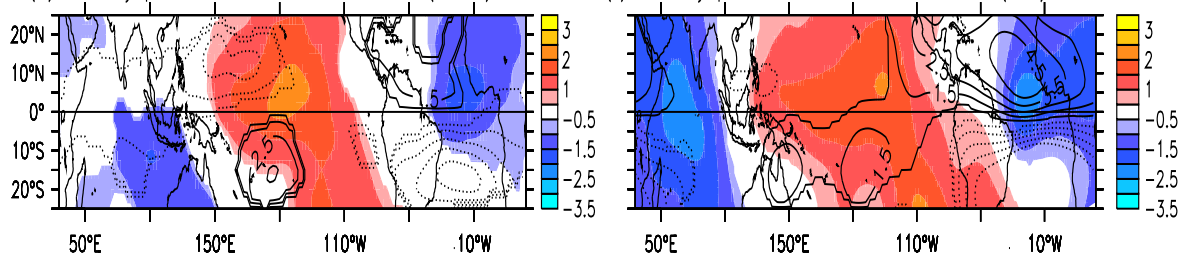

(g) SLP and 500hPo omego (NCEP)

(h) SLP and 500hPo omego (MPI)
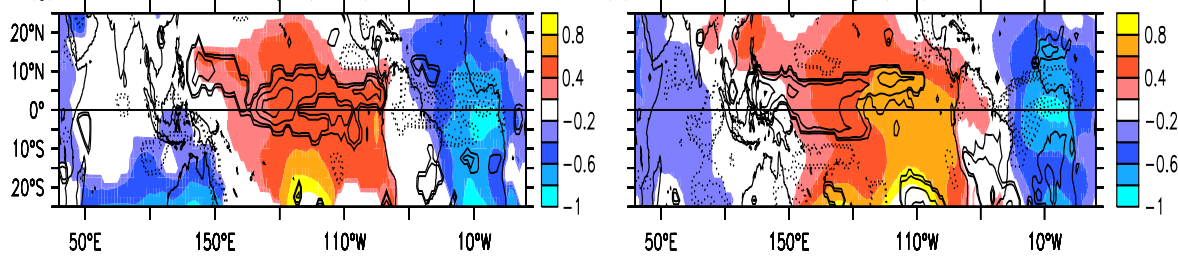

Fig. 2 (a, b) Sea surface temperature (contour) and precipitation (shading), (c, d) thermocline depth (shading) and wind stress (vector), (e, f) stream function (contour) and velocity potential (shading) and $(\mathrm{g}, \mathrm{h})$ sea level pressure (shading) and vertical velocity (contour) at the $500 \mathrm{hPa}$ in boreal summer regressed onto boreal summer Atlantic cold tongue SST. On the left panels, quantities are from observations (HadISST and Xie and Arkin (1997)) and NCEP reanalysis (Kalnay et al (1996)). On the left panels, quantities are from model ensemble mean. The units for precipitation, thermocline depth, wind stress, velocity potential and sea level pressure are $m m d a y^{-1}, m, \mathrm{Nm}^{-2}$, $10^{6} \mathrm{~m}^{2} \mathrm{~s}^{-1}$ and $h \mathrm{~Pa}$, respectively. The contour interval of SST is $0.2^{\circ} \mathrm{C}$. The contours shown for stream function (vertical velocity) are $\pm 4.5, \pm 3.5, \pm 2.5, \pm 1.5$ and $\pm 0.5 \times 10^{6} \mathrm{~m}^{2} \mathrm{~s}^{-1}$ $\left( \pm 2.5, \pm 2.0, \pm 1.5, \pm 1.0, \pm 0.5\right.$ and $\left.\pm 0.25 \times 10^{-2} \mathrm{Pas}^{-1}\right)$. Positive and negative values are shown by solid and dashed curves, respectively. Note that negative vertical velocity mean upward motions. Only those values which are over $95 \%$ statistically significant under a Student t-test are shown. 
(a) SST and precipitation (OBS)

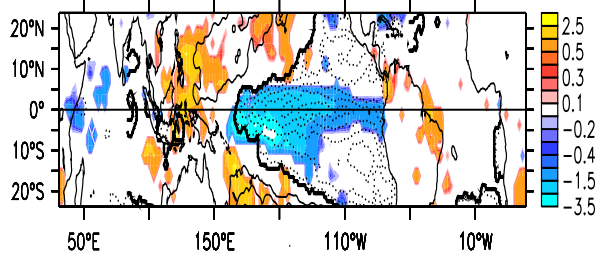

(b) SST and precipitation (MPI)

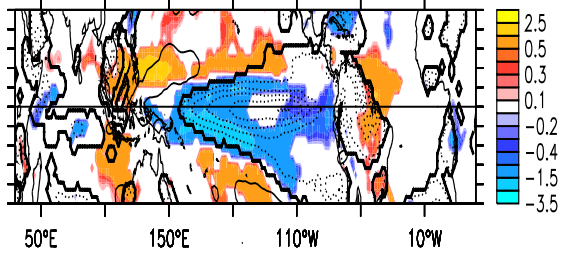

(d) Z20 and wind stress (MPI)

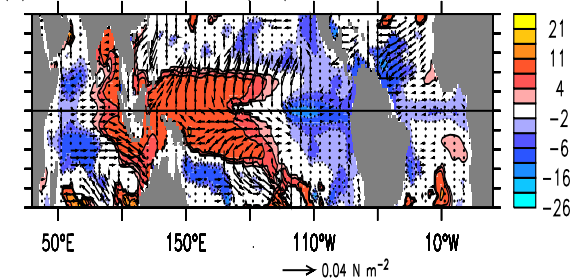

(f) Velocity potential and streamfunction (MPI)
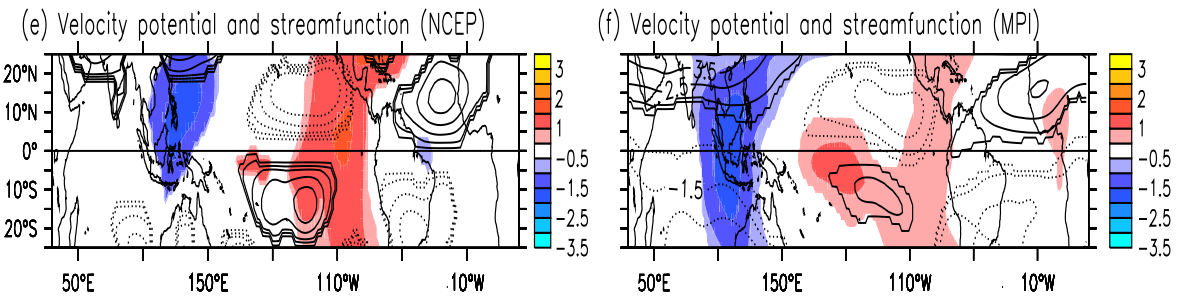

(g) SLP and 500hPo omego (NCEP)

(h) SLP and 500hPo omego (MPI)
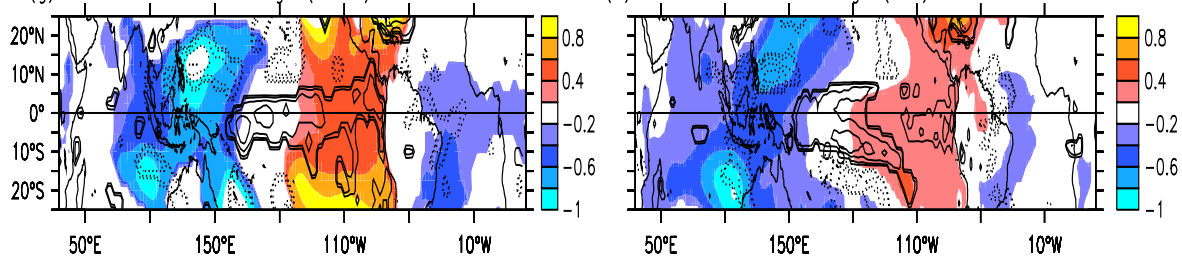

Fig. 3 The same as in fig. 2 except that all of the quantities from boreal winter are regressed onto boreal summer Atlantic cold tongue SST. 


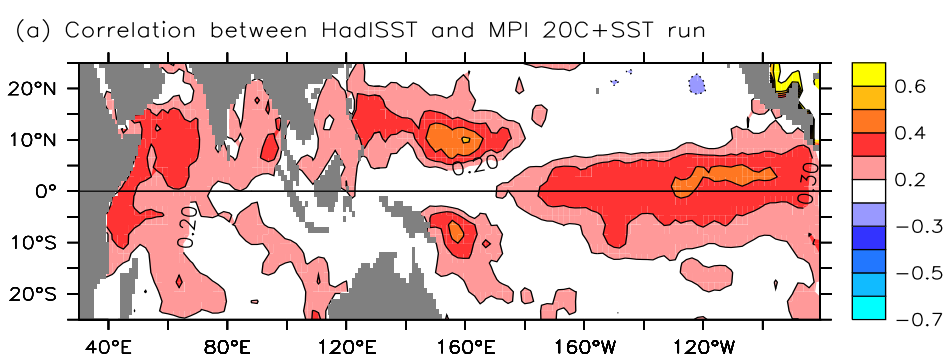

(b) Nino3 SST monthly stratified correlation

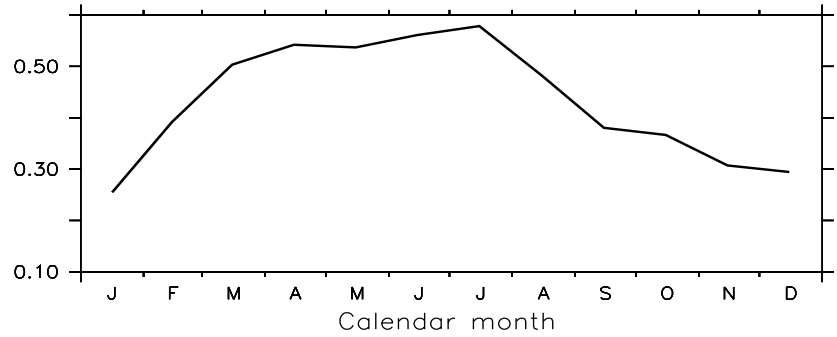

(c) Correlation in Z20 between NCEP and MPI 20C+SST run

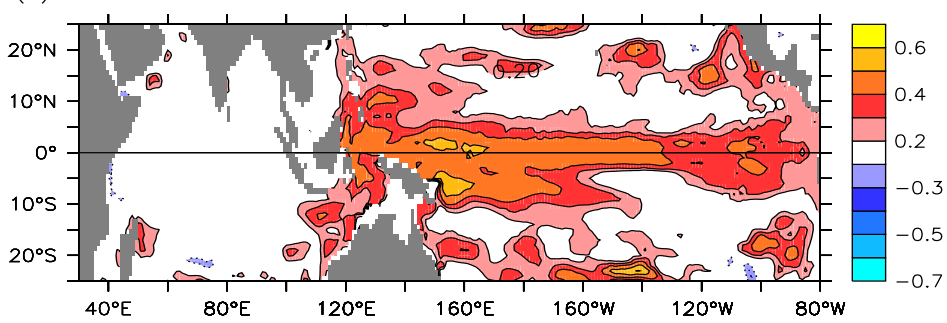

Fig. 4 (a) Correlation between observed (HadISST) SST and the ensemble mean SST simulated by the MPI model with observed SST prescribed in the Atlantic. (b) As in (a) except for Niño3 SST and for individual calendar months. (c) As in (a) except for thermocline depth between NCEP reanalysis and MPI model. 
(a) Cross correlation: Nino3 Vs Atlantic cold tongue SST before 1970

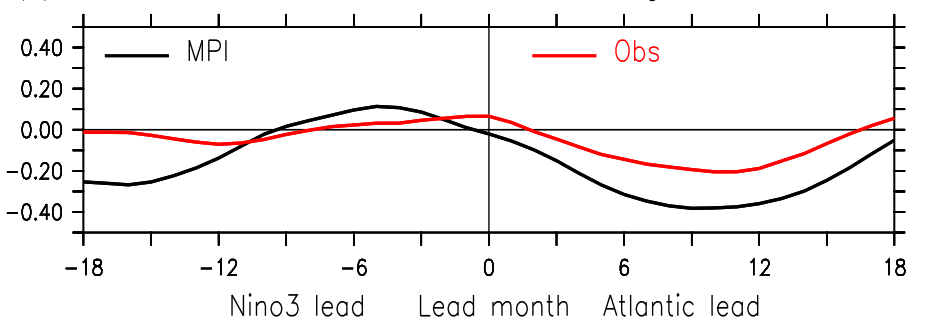

(b) Cross correlation: Nino3 Vs Atlantic cold tongue SST 1970 to 2005

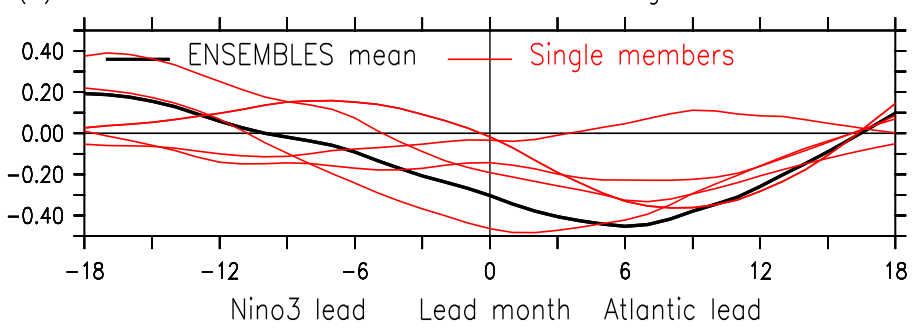

Fig. 5 (a) as in Fig. 1 except for HadISST (1900-1970) and ensemble mean (1955-1970)

(b) as in Fig. 1 except only for model ensemble mean (black) and single ensemble members (red) from 1970 to 2005. 
Acknowledgements The work was supported by the German BMBF NORDATLANTIK project and the SFB 754 of DFG. NSK is funded by the DFG Emmy Noether Programme. The coupled model was run at ECMWF. Figures were created using Ferret, a product of NOAA's Pacific Marine Environmental Laboratory. 


\section{References}

Bjerknes J (1969) Atmospheric Teleconnections from the Equatorial PACIFIC1. Mon Wea Rev 97(3):163, DOI 10.1175/15200493(1969)097<0163:ATFTEP>2.3.CO;2

Carton J, Huang B (1994) Warm Events in the Tropical Atlantic. J Phys Oceanogr 24(5):888-903, DOI 10.1175/15200485(1994)024<0888:WEITTA > 2.0.CO;2

Carton J, Cao X, Giese B, Da Silva A (1996) Decadal and interannual SST variability in the tropical Atlantic Ocean. J Phys Oceanogr 26(7):1165-1175, DOI 10.1175/1520-0485(1996)026<1165:DAISVI $>2.0 . \mathrm{CO} ; 2$

Chang P, Fang Y, Saravanan R, Ji L, Seidel H (2006) The cause of the fragile relationship between the Pacific El Niño and the Atlantic Niño. Nature 443(7109):324, DOI 10.1038/nature05053

Chiang J, Lintner B (2005) Mechanisms of remote tropical surface warming during El Niño. J Climate 18(20):4130-4149, DOI 10.1175/JCLI3529.1

Chiang J, Sobel A (2002) Tropical tropospheric temperature variations caused by ENSO and their influence on the remote tropical climate. J Climate 15(18):18, DOI 10.1175/1520-0442(2002)015<2616:TTTVCB >2.0.CO;2

Davey M, Huddleston M, Sperber K, Braconnot P, Bryan F, Chen D, Colman R, Cooper C, Cubasch U, Delecluse P, et al (2002) STOIC: a study of coupled model climatology and variability in tropical ocean regions. Climate Dyn 18(5):403-420, DOI 10.1007/s00382-001-0188-6 
Ding H, Keenlyside N, Latif M (2010) Equatorial Atlantic interannual variability: the role of heat content. J Geophys Res 115(C9):C09,020, DOI 10.1029/2010JC006304, in press

Enfield D, Mayer D (1997) Tropical Atlantic sea surface temperature variability and its relation to El Nino-Southern Oscillation. J Geophys Res 102(C1):929-945, DOI 10.1029/96JC03296

Glantz M, Katz R, Nicholls N (1991) Teleconnections linking worldwide climate anomalies. Cambridge University Press Cambridge

Jansen M, Dommenget D, Keenlyside N (2009) Tropical atmosphere-ocean interactions in a conceptual framework. Journal of Climate 22(3):550-567, DOI 10.1175/2008JCLI2243.1

Jin F (1997) An Equatorial Ocean Recharge Paradigm for ENSO. Part I: Conceptual Model. J Atmos Sci 54(7):811-829, DOI 10.1175/15200469(1997)054<0811:AEORPF >2.0.CO;2

Jungclaus J, Keenlyside N, Botzet M, Haak H, Luo J, Latif M, Marotzke J, Mikolajewicz U, Roeckner E (2006) Ocean circulation and tropical variability in the coupled model ECHAM5/MPI-OM. J Climate 19(16):3952-3972, DOI 10.1175/JCLI3827.1

Kalnay E, Kanamitsu M, Kistler R, Collins W, Deaven D, Gandin L, Iredell M, Saha S, White G, Woollen J, et al (1996) The NCEP/NCAR 40-Year Reanalysis Project. Bull Am Meteorol Soc 77(3):437-471, DOI 10.1175/15200477(1996)077<0437:TNYRP > 2.0.CO;2 
Keenlyside N, Latif M (2007) Understanding Equatorial Atlantic Interannual Variability. J Climate 20(1):131-142, DOI 10.1175/JCLI3992.1

Keenlyside N, Latif M, Jungclaus J, Kornblueh L, Roeckner E (2008) Advancing decadal-scale climate prediction in the North Atlantic sector. Nature 453(7191):84-88, DOI 10.1038/nature06921

Klein S, Soden B, Lau N (1999) Remote sea surface temperature variations during ENSO: Evidence for a tropical atmospheric bridge. J Climate 12(4):917-932, DOI 10.1175/1520-0442(1999)012;0917:RSSTVD ¿2.0.CO;2

Kozlenko S, Mokhov I, Smirnov D (2009) Analysis of the cause and effect relationships between El Niño in the Pacific and its analog in the equatorial Atlantic. Izvestiya Atmospheric and Oceanic Physics 45(6):704-713, DOI 10.1134/S0001433809060036

Krishnamurthy V, Kirtman B (2006) Variability of the Indian Ocean: Relation to monsoon and ENSO. Quart J Roy Meteor Soc 129(590):1623-1646, DOI 10.1256/qj.01.166

Kucharski F, Bracco A, Yoo J, Molteni F (2007) Low-Frequency Variability of the Indian Monsoon-ENSO Relationship and the Tropical Atlantic: The" Weakening" of the 1980s and 1990s. J Climate 20(16):4255, DOI 10.1175/JCLI4254.1

Kucharski F, Bracco A, Yoo J, Molteni F (2008) Atlantic forced component of the Indian monsoon interannual variability. Geophys Res Lett 33(4):L04,706, DOI 10.1029/2007GL033037 
Kucharski F, Bracco A, Yoo J, Tompkins A, Feudale L, Ruti P, Dell'Aquila A (2009) A Gill-Matsuno-type mechanism explains the tropical Atlantic influence on African and Indian monsoon rainfall. Quart J Roy Meteor Soc 135(640):569-579, DOI 10.1002/qj.406

Latif M, Barnett T (1995) Interactions of the tropical oceans. J Climate 8(4):952-965, DOI 10.1175/1520-0442(1995)008<0952:IOTTO >2.0.CO;2

Latif M, Grötzner A (2000) The equatorial Atlantic oscillation and its response to ENSO. Climate Dyn 16(2):213-218, DOI 10.1007/s003820050014

Losada T, Rodríguez-Fonseca B, Polo I, Janicot S, Gervois S, Chauvin F, Ruti P (2009) Tropical response to the Atlantic Equatorial mode: AGCM multimodel approach. Climate Dyn 33(1):1-8, DOI 10.1007/s00382-009-0624-6

Philander S (1990) El Niño, La Niña, and the southern oscillation. Academic $\operatorname{Pr}$

Rayner N, Parker D, Horton E, Folland C, Alexander L, Rowell D, Kent E, Kaplan A (2003) Global analyses of sea surface temperature, sea ice, and night marine air temperature since the late nineteenth century. J Geophys Res 108(D14):4407-4453, DOI 10.1029/2002JD002670

Richter I, Xie S (2008) On the origin of equatorial Atlantic biases in coupled general circulation models. Climate Dyn 31(5):587-598, DOI 10.1007/s00382-008-0364-z

Rodríguez-Fonseca B, Polo I, García-Serrano J, Losada T, Mohino E, Mechoso C, Kucharski F (2009) Are Atlantic Niños enhancing Pacific ENSO events in recent decades? Geophys Res Lett 36(20):L20,705, DOI 
10.1029/2009GL040048

Ruiz-Barradas A, Carton J, Nigam S (2000) Structure of
interannual-to-decadal climate variability in the tropical At-
lantic sector. J Climate $13(18): 3285-3297$, DOI $10.1175 / 1520-$
$0442(2000) 013<3285$ :SOITDC $>2.0 . \mathrm{CO} ; 2$

Valcke S, Caubel A, Declat D, Terray L (2003) OASIS3 ocean atmosphere sea ice soil. Users guide Prisim project report 2

Wagner R, Da Silva A (1994) Surface conditions associated with anomalous rainfall in the Guinea coastal region. Int J Climatol 14(2):179-199, DOI 10.1002/joc.3370140205

Wahl S, Latif M, Park W, Keenlyside N (2009) On the Tropical Atlantic SST warm bias in the Kiel Climate Model. Climate Dynamics 33(6):174, DOI $10.1007 / \mathrm{s} 00382-009-0690-9$

Wang C (2006) An overlooked feature of tropical climate: Inter-PacificAtlantic variability. Geophysical Research Letters 33(12):L12,702, DOI 10.1029/2006GL026324

Wang C, Kucharski F, Barimalala R, Bracco A (2009) Teleconnections of the tropical Atlantic to the tropical Indian and Pacific Oceans: A review of recent findings. Meteorologische Zeitschrift 18(4):445-454, DOI 10.1127/0941$2948 / 2009 / 0394$

Xie P, Arkin P (1997) Global precipitation: A 17-year monthly analysis based on gauge observations, satellite estimates, and numerical model outputs. Bull Am Meteorol Soc 78(11):2539-2558, DOI 10.1175/1520- 
0477(1997)078<2539:GPAYMA > 2.0.CO;2

Xie S, Carton J (2004) Tropical Atlantic variability: Patterns, mechanisms, and impacts. Earth's Climate: The Ocean-Atmosphere Interaction, Geophys Monogr 147:121-142

Xie SP, Annamalai H, Schott FA, McCreary JP (2002) Structure and mechanisms of south indian ocean climate variability*. Journal of Climate 15(8):864-878, DOI 10.1175/1520-0442(2002)015¡0864:SAMOSI ¿2.0.CO;2

Zebiak S (1993) Air-Sea Interaction in the Equatorial Atlantic Region. J Climate 6(8):1567-1586, DOI 10.1175/15200442(1993)006<1567:AIITEA > 2.0.CO;2 